\title{
A rational approach to the diagnosis of polycystic ovarian syndrome during adolescence
}

\author{
Uma abordagem racional do diagnóstico da síndrome \\ dos ovários policísticos na adolescência
}

Paulina M. Merino ${ }^{1,2}$, Ethel Codner', Fernando Cassorla'

${ }^{1}$ Institute of Maternal and Child Research (IDIMI), School of Medicine, University of Chile, Chile ${ }^{2}$ Department of Pediatrics, Campus Centro, School of Medicine, University of Chile, Chile
Correspondence to: Paulina M. Merino Institute of Maternal and Child Research (I.D.I.M.I.), School of Medicine, University of Chile, Casilla 226-3, Santiago, Chile pmmerino@gmail.com

Received on 9/Oct/2011 Accepted on 19/Oct/2011

\section{SUMMARY}

Polycystic ovarian syndrome (PCOS) is a lifelong disorder characterized by hyperandrogenism and ovulatory dysfunction, with a wide spectrum of clinical symptoms and signs. Three different sets of diagnostic criteria have been established in order to define this disease in adult women, but there is controversy regarding the use of these criteria in adolescence. During puberty, the adult criteria for ovulatory dysfunction does not seem applicable, because an irregular menstrual pattern and a decreased ovulatory rate is a physiologic event during this period of life. Also, a higher prevalence of polycystic ovarian morphology (PCOM) may be observed during this period, so PCOM is not a useful criterion to define PCOS in young women. These findings suggest that a key factor to diagnose to PCOS during adolescence is hyperandrogenism. In addition, since PCOM is not clearly associated with hyperandrogenism during this period of life, the term "polycystic ovarian syndrome" during adolescence creates confusion and may be misleading. Arq Bras Endocrinol Metab. 2011;55(8):590-8

\section{Keywords}

Hyperandrogenism; hirsutism; polycystic ovarian syndrome; adolescence; diagnosis; puberty; polycystic ovarian morphology; menstrual irregularities; anti-Müllerian hormone

\section{SUMÁRIO}

A síndrome dos ovários policísticos (SOP) é uma desordem que afeta pacientes por toda a vida e é caracterizada por hiperandrogenismo e disfunção ovariana, com um amplo leque de sintomas e sinais clínicos. Três diferentes conjuntos de critérios diagnósticos foram estabelecidos para definir essa doença em mulheres adultas, mas existem controvérsias relacionadas ao uso desses critérios na adolescência. Durante a puberdade, o critério de disfunção ovariana usado em adultos não parece aplicável, porque um padrão menstrual irregular e uma menor taxa de ovulação são eventos fisiológicos nesse período da vida. Além disso, uma maior prevalência de morfologia ovariana policística (MOP) pode ser observada nesse período, de forma que a MOP não é um critério útil para se definir a SOP em mulheres jovens. Esses achados sugerem que o hiperandrogenismo é um fator-chave para o diagnóstico da SOP na adolescência. Além disso, como a MOP não está claramente associada com o hiperandrogenismo durante esse período da vida, o termo "síndrome dos ovários policísticos" durante a adolescência cria confusão e pode ser errôneo. Arq Bras Endocrinol Metab. 2011;55(8):590-8

\section{Descritores}

Hiperandrogenismo; hirsutismo; síndrome dos ovários policísticos; adolescência; diagnóstico; puberdade; morfologia ovariana policística; irregularidades menstruais; hormônio antiMülleriano 


\section{INTRODUCTION}

$\mathrm{P}$ olycystic ovarian syndrome (PCOS) is an endocrine and metabolic disorder that affects $5 \%$ to $7 \%$ of women in reproductive age (1). It is a lifelong disorder with different clinical manifestations across the lifespan, but it is often diagnosed during late adolescence, with anovulation and hyperandrogenism. The prevalence of this disorder during adolescence has not been established, because the symptoms and signs that define this condition often overlap with the physiological changes of the reproductive axis that occur in normal girls during this period $(2,3)$.

We will review the three sets of diagnostic criteria of PCOS, which have been developed for adult women, and we will discuss whether these criteria are applicable to adolescent girls.

\section{DEFINITION}

The first description of PCOS was made by Irving Stein and Michael Leventhal in 1935, who described 7 adult women with amenorrhea, hirsutism, obesity and ovaries with "bilateral cystic degeneration" (4). The presence of this ovarian pattern was central in the initial description of these patients and led to the name of the syndrome, but it was later found that other patients with more subtle forms of PCOS, exhibit variable clinical and laboratory findings. The heterogeneity of PCOS has led to multiple groups of experts trying to establish a better definition, based on solid scientific evidence and useful from a clinical point of view (Table 1 ). During the last 20 years, three separate groups of experts have established three different sets of diagnostic criteria, based in the presence of ovulatory dysfunction, clinical and biochemical hyperandrogenism, and ultrasonographic features of polycystic ovaries as diagnostic elements. The presence of clinical or biochemical hyperandrogenism, is required by two of the three existing classifications in order to make the diagnosis of PCOS.

The first attempt to reach a consensus on the definition of PCOS was made by the National Institutes of Health (NIH), in the United States, which in 1990 organized a meeting of experts to establish the diagnostic criteria for this syndrome (5). At this conference, a questionnaire was sent to a large number of experts in order to define their diagnostic criteria for PCOS. The meeting involved 58 researchers, and PCOS was defined by those criteria with at least $40 \%$ agreement. The survey showed that hyperandrogenemia was mentioned by $64 \%$ of the participants, the exclusion of other conditions by $60 \%$, menstrual dysfunction by $52 \%$ and clinical hyperandrogenism (HA) by $48 \%$ of the experts. Following these results, the consensus reached by the NIH concluded that PCOS should be defined as a clinical disorder characterized by clinical and/or biochemical hyperandrogenism associated with a menstrual disorder, and that to make an accurate diagnosis, other conditions such as Cushing syndrome, congenital adrenal hyperplasia and hyperprolactinemia should be excluded (5).

These criteria were used to diagnose PCOS primarily in the United States, because European experts rejected the exclusion of ultrasound as a diagnostic criteria. Thus, in 2003, a meeting of experts sponsored by the European Society of Human Reproduction and Embryology and the American Society for Reproductive Medicine met in the city of Rotterdam to review the available data regarding the diagnosis of PCOS in adult women.

This panel of experts introduced the concept that polycystic ovarian morphology (PCOM) detected by ultrasound should be considered as a diagnostic criterion, thus broadening the clinical spectrum of PCOS. The Rotterdam consensus defined PCOS as patients who met two of three criteria: clinical or biochemical hyperandrogenism, oligo-anovulation and PCOM. This definition added two new phenotypes to those described by the NIH Consensus: women with anovulation and PCOM without hyperandrogenism or hyperandrogenism, and PCOM with normal ovulatory cycles. The diagnosis of PCOS, however, in the latter group of patients who do not have hyperandrogenism, has led to significant controversy among endocrinologists (6).

Because of these difficulties in the diagnosis of PCOS, the Androgen Excess Society (AES) decided to appoint an expert panel to review the literature using criteria derived from "evidence-based medicine". This panel of experts assessed the literature regarding the possible association of different phenotypes of PCOS with long-term morbidity. This consensus, which differs in the survey methodology employed by the NIH or by the meeting of experts in Rotterdam, observed that only the patients with clinical and/or biochemical hyperandrogenism have increased long-term metabolic and cardiovascular risk, and that therefore the diagnosis 
of PCOS in adult women requires the presence of hyperandrogenism. The AES published in 2006 these new diagnostic criteria that require the obligatory presence of hyperandrogenism, with either PCOM or oligo/anovulation in order to make the diagnosis of PCOS (Table 1) $(7,8)$. The three classifications of PCOS, which have been developed for adults, are consistent in that neither the presence of insulin resistance, nor increased $\mathrm{LH} / \mathrm{FSH}$ concentrations, nor the presence of excess weight or obesity are diagnostic elements of PCOS. Also, all definitions agree on the need to exclude other conditions that could mimic this syndrome (8).

\section{CRITERIA TO DIAGNOSE PCOS IN THE ADOLESCENT GIRL}

The three different sets of diagnostic criteria established to define PCOS are based in studies performed in adult patients. During adolescence, many features of this syndrome can also be observed in normal girls as physiological stages related to the maturation of the hypothalamus-pituitary-ovarian axis.

\section{Ovulatory or menstrual dysfunction}

Oligomenorrhea in adult women is defined as the presence of less than 9 menstrual periods per year, or 3 cycles greater than 38 days during the past year, and amenorrhea is defined as cycles over 90 days (9). However, the presence of regular menstrual cycles in women with hyperandrogenism does not ensure the presence of ovulation, since $40 \%$ of these women have oligo-anovulation when laboratory tests are performed. Thus, the AES and Rotterdam groups suggested that ovulatory dysfunction in adult women must be documented by the measurement of progesterone on days 20 to 24 of the menstrual cycle. In adolescence, menstrual cycles are frequently longer, and anovulation is physiological, thus complicating the use of this criteria.

Table 1. Diagnostic criteria for PCOS according to different published definitions. Modified from Ethel Codner and Héctor F. Escobar-Morreale. Hyperandrogenism and polycystic ovary syndrome in women with Type 1 diabetes mellitus. J Clin Endocrinol Metab. 2007;92:1209-16.

\begin{tabular}{|c|c|c|c|c|c|c|}
\hline Definition/year & Diagnostic criteria & $\begin{array}{c}\text { Possible } \\
\text { phenotypes }\end{array}$ & Exclusion criteria & $\begin{array}{c}\text { Clinical } \\
\text { hyperandrogenism }\end{array}$ & $\begin{array}{c}\text { Biochemical } \\
\text { hyperandrogenism }\end{array}$ & PCOM \\
\hline $\mathrm{NIH} / 1990$ & $\begin{array}{l}\text { Requires the } \\
\text { simultaneous } \\
\text { presence of: 1) } \\
\text { clinical and/or } \\
\text { biochemical } \\
\text { hyperandrogenism, } \\
\text { and 2) menstrual } \\
\text { dysfunction }\end{array}$ & $\begin{array}{l}\text { 1) Clinical and/or } \\
\text { biochemical } \\
\text { hyperandrogenism + } \\
\text { menstrual dysfunction }\end{array}$ & $\begin{array}{l}\text { Congenital adrenal } \\
\text { hyperplasia, androgen } \\
\text { secreting tumors, } \\
\text { Cushing's syndrome, } \\
\text { hyperprolactinemia }\end{array}$ & $\begin{array}{l}\text { Hirsutism, alopecia, } \\
\text { acne }\end{array}$ & $\begin{array}{l}\text { 1) Total testosterone, } \\
\text { 2) Free testosterone, } \\
\text { 3) Androstenedione, } \\
\text { 4) DHEAS }\end{array}$ & Not included \\
\hline Rotterdam/2003 & $\begin{array}{l}\text { Requires the presence } \\
\text { of at least } 2 \text { criteria: } 1 \text { ) } \\
\text { clinical and/or } \\
\text { biochemical } \\
\text { hyperandrogenism, 2) } \\
\text { menstrual } \\
\text { dysfunction, and 3) } \\
\text { PCOM }\end{array}$ & $\begin{array}{l}\text { 1) Clinical and/or } \\
\text { biochemical } \\
\text { hyperandrogenism } \\
\text { +oligoanovulation, 2) } \\
\text { Clinical and/or } \\
\text { biochemical } \\
\text { hyperandrogenism } \\
\text { +oligoanovulation + } \\
\text { PCOM, 3) Clinical } \\
\text { and/or biochemical } \\
\text { hyperandrogenism } \\
\text { +PCOM, 4) PCOM + } \\
\text { oligoanovulation }\end{array}$ & $\begin{array}{l}\text { Congenital adrenal } \\
\text { hyperplasia, androgen } \\
\text { secreting tumors, } \\
\text { Cushing's syndrome }\end{array}$ & $\begin{array}{l}\text { Hirsutism, acne and } \\
\text { androgenic alopecia? }\end{array}$ & $\begin{array}{l}\text { 1) Total testosterone, } \\
\text { 2) Free androgen } \\
\text { index or free } \\
\text { testosterone, } \\
\text { 3) DHEAS }\end{array}$ & $\begin{array}{l}\text { At least one ovary } \\
\text { with: 1) } 12 \text { or more } \\
\text { follicles (2-9 mm in } \\
\text { diameter) or 2) } \\
\text { Ovarian volume } \\
>10 \mathrm{ml}\end{array}$ \\
\hline AES/2006 & $\begin{array}{l}\text { Requires the presence } \\
\text { of hyperandrogenism, } \\
\text { clinical and/or } \\
\text { biochemical, and } \\
\text { either 1) oligo- } \\
\text { anovulation or 2) } \\
\text { PCOM }\end{array}$ & $\begin{array}{l}\text { 1) Clinical and/or } \\
\text { biochemical } \\
\text { hyperandrogenism } \\
\text { +oligoanovulation, 2) } \\
\text { Clinical and/or } \\
\text { biochemical } \\
\text { hyperandrogenism } \\
\text { +oligoanovulation + } \\
\text { PCOM, 3) 1) Clinical } \\
\text { and/or biochemical } \\
\text { hyperandrogenism } \\
+ \text { PCOM }\end{array}$ & $\begin{array}{l}\text { Congenital adrenal } \\
\text { hyperplasia, androgen } \\
\text { secreting tumors, } \\
\text { androgenic/anabolic } \\
\text { drugs, Cushing's } \\
\text { syndrome, syndromes } \\
\text { of severe insulin } \\
\text { resistance, thyroid } \\
\text { dysfunction, } \\
\text { hyperprolactinemia }\end{array}$ & Hirsutism & $\begin{array}{l}\text { 1) Total testosterone, } \\
\text { 2) Free androgen } \\
\text { index or free } \\
\text { testosterone, } \\
\text { 3) DHEAS, } \\
\text { 4) Androstenedione }\end{array}$ & $\begin{array}{l}\text { At least one ovary } \\
\text { with: 1) } 12 \text { or more } \\
\text { follicles (2-9 mm in } \\
\text { diameter) or 2) } \\
\text { Ovarian volume } \\
>10 \mathrm{ml}\end{array}$ \\
\hline
\end{tabular}


During the early postmenarche (PM) years, the menstrual cycles can last between 21 and 45 days (10). The characteristic menstrual regularity of the adult female (24-38 days) is usually reached several years following menarche. According to the AAP/ACOG, the persistent presence of cycles longer than 45 days, suggest the presence of ovulatory dysfunction in adolescent girls (11). There are some data, however, that the persistence of oligomenorrhea 3-5 years following menarche can be related to the appearance of signs suggestive of PCOS.

In a study of Chilean adolescents, the mean menstrual cycle length was $45.4 \pm 24.8$ days with $25 \%$ of ovulatory cycles in the first year following menarche. The mean duration of the cycles decreased to $32.6 \pm$ 5.1 and $32.2 \pm 4.7$ in the third and fourth years after menarche, with an ovulatory rate of $37 \%$ and $45 \%$, respectively. This ovulatory rate was documented by a salivary progesterone $>0.06 \mathrm{ng} / \mathrm{mL}$, obtained on days $13,18,23$, and 28 of each menstrual cycle (12). Thus, the measurement of serum progesterone on day 20-24 of the cycle to diagnose ovulation may be misleading.

Therefore, because of the lower ovulatory rate and longer menstrual cycles during this period of life, it is necessary to consider different criteria to diagnose PCOS during adolescence. We suggest that the absence of menstrual periods for periods exceeding 90 days, or by persistent cycles longer than 45 days suggest the presence of ovulatory dysfunction in an adolescent.

\section{Hiperandrogenism (HA)}

HA has been considered the most important sign of PCOS, because of its relationship to long-term metabolic and cardiovascular risk in adult women with PCOS (6). As previously mentioned, HA can be clinical or biochemical.

Clinical hyperandrogenism results from an excess or hypersensitivity to androgens, and may include hirsutism, seborrhea, acne and androgenic alopecia. The NIH and Rotterdam classifications consider hirsutism, acne and alopecia as signs of hyperandrogenism. In contrast, the AES classification only accepts the presence of hirsutism as a genuine marker of HA. During adolescence hirsutism is considered the best marker for HA. Acne is a common transient finding in normal adolescents, and alopecia is very uncommon in the pediatric population.

Hirsutism is the most specific sign of clinical HA, and is defined as an increase in terminal hair in androgen-dependent areas (upper lip, chin, upper and lower back, anterior chest, upper and lower abdomen, arms and thighs) $(13,14)$. In order to define hirsutism, the modified Ferriman and Gallwey score has been proposed $(15,16)$. Hirsutism is defined by a Ferriman score equal or greater than 8 , which corresponds to the 95 th percentile for European populations. Other studies in less hirsute populations have used a cutoff of 6 and in some cases even of 3 (17-19). The cutoff for defining hirsutism during adolescence may be lower, due to the short exposure to androgens. The Ferriman score in the Raine cohort showed that $92 \%$ of adolescents have a score below 5 , and that $58 \%$ have a score of zero (20).

It is important to make the distinction of hirsutism with hypertrichosis, which is not considered a manifestation of androgen excess. Hypertrichosis is a frequent finding in prepubertal girls, and differs from hirsutism in the quality of the hair, and in its anatomic distribution in androgen and non-androgen-dependent sensitive areas. A study performed in Latin American girls suggests that hypertrichosis may be secondary to a slight increase in total testosterone, and an increase in peripheral $5 \alpha$-reductase activity (21).

Acne is considered by the NIH and Rotterdam groups as a manifestation of androgen excess, but not by the AES. Overall, although acne affects $15 \%$ to $25 \%$ of PCOS patients, it is unclear whether the prevalence of acne is significantly increased in these patients compared to the general population (22). Acne may be considered as HA during adolescence in some situations, such as in the presence of persistent comedones in prepubertal girls, in cases of widespread severe acne, and in cases who lack a response to standard treatment (23).

Alopecia is very uncommon in the pediatric population. A recent retrospective series of 438 pediatric patients (boys and girls) demonstrated that androgenetic alopecia (AGA) is the cause of alopecia in $13 \%$ of children and $42 \%$ of adolescents. Of the 57 pediatric patients studied, 19 were female, and $32 \%$ were premenarcheal. In this group of girls with AGA, 9 patients had the clinical diagnosis of classic PCOS, but only 4 had additional hirsutism (24). Androgenic alopecia affects only $5 \%$ of women with hyperandrogenism, and thus is not considered a diagnostic criterion for HA by the AES (25). In addition, when not associated with hirsutism or acne, alopecia is a non-specific sign, which may caused by other etiologies unrelated to hyperandrogenism, like alopecia areata, which is the most common cause in the pediatric population (24). 
Biochemical hyperandrogenism is accepted by the three classifications as a central element for the diagnosis of PCOS (Table 1). The three classifications are consistent that biochemical hyperandrogenism should be documented by measuring total testosterone, dehydroepiandrosterone sulfate (DHEAS), and free androgens, either by determining free testosterone or by calculation of the free androgen index. There is less consensus on whether to measure serum androstenedione, or free testosterone, which has significant methodological problems, because the determination of free testosterone by direct radioimmunoassay (RIA) may be inaccurate $(8,26,27)$.

For these reasons, the Rotterdam consensus supports the calculation of the free androgen index (FAI) that correlates well with the levels of free testosterone measured by equilibrium dialysis, and has excellent sensitivity and specificity in women with PCOS (28). As with total testosterone, there is no consensus regarding the FAI cutoff point to diagnose hyperandrogenism (29). The variability in methods to measure total testosterone complicates the definition of an universal cutoff point to define biochemical hyperandrogenism in adult women, but there are some data that a highquality RIA assay for total testosterone might be useful clinically, because it correlates well with gas (GC-MS) or liquid (LC- MS) chromatography-mass spectrometry (30-32).

During adolescence, serum testosterone concentrations are higher than during adulthood, reaching a peak during the second decade of life (33). The problem to define biochemical HA during adolescence is related to the physiological increase in androgen levels during puberty, which is associated with lower SHBG levels, thus increasing free androgens $(29,34)$. The presence of signs of insulin resistance (higher waist circumference and lower SHBG) as well as hyperandrogenemia (increased FAI) has been associated with irregular menstrual cycles and with an hyperandrogenic phenotype in a group of Hispanic adolescents (34).

Other signs suggestive of hyperandrogenism in childhood and adolescence are early pubarche, and premature adrenarche (35). In these cases, it is important to exclude other sources of androgens, such as adrenal disorders (congenital adrenal hyperplasia and Cushing syndrome), virilizing tumors (ovarian, adrenal), and other endocrinopathies (acromegaly, HAIR-AN, thyroid disorders etc.).

\section{Polycystic ovarian morphology}

Polycystic ovarian morphology (PCOM) has been considered as an important element for the diagnosis of polycystic ovarian syndrome in adult women, by both the Rotterdam and AES groups $(6,36)$. The definition of PCOM emanates from studies that looked for sonographic criteria which were associated with clinical hyperandrogenism, and with PCOS as defined by classic criteria in adult women $(37,38)$. The Rotterdam Consensus defined PCOM as the presence of 12 or more follicles of 2 to $9 \mathrm{~mm}$ in diameter, and/or an ovarian volume greater than $10 \mathrm{ml}$ in at least one ovary. The subjective aspect of the ovaries, their follicular distribution or the appearance of the stroma is not considered as important. The sensitivity and specificity of these cutoffs to diagnose PCOS in adult women has been assessed with transvaginal ultrasound, that has better resolution than the transabdominal route, which is frequently used in adolescents (39).

A high prevalence of PCOM in healthy adolescents, with regular menstrual cycles and with no evidence of clinical hyperandrogenism, has been reported in the $30 \%-35 \%$ range (40-42), which is similar to the prevalence of $38 \%$ and $37 \%$ observed in adolescents with hyperandrogenism and or PCOS, respectively, but is lower compared to the prevalence of PCOM 90\%$100 \%$ in adult women with PCOS (17). Thus, these findings suggest that PCOM during adolescence is not increased in hyperandrogenic adolescents compared to healthy girls, and is less prevalent in the former group compared to adult women with PCOS.

The hormonal profile associated with the presence of PCOM has shown that this condition, when observed in healthy girls with regular menstrual cycles, is not associated with insulin resistance or hyperandrogenism $(40,43,44)$. However, Mortensen and cols. showed mild ovarian dysfunction in some girls with PCOM, which was not later confirmed by Codner and cols. $(43,45)$.

There are some data that this ultrasonographic finding is frequent in young women and decreases with age (46-48). In adults, this sonographic finding may be present in $10 \%$ to $20 \%$ of healthy women with regular menstrual cycles and without clinical hyperandrogenism $(49,50)$. Moreover, the presence of PCOM may change over time in the same patient. Our longitudinal study in healthy non-obese, non-hyperandrogenic adolescents between 2 and 4 years postmenarche showed that PCOM is present in $33 \%$ of girls at 2, 3 and 4 years 
postmenarche (Figure 1, with permission) (43). Similarly, Adams and cols. showed a low concordance for PCOM over a five year follow-up in adult women (51).

Numerous studies have looked for a surrogate marker of PCOM in adult patients with PCOS. AntiMüllerian hormone (AMH), a glycoprotein secreted by the granulosa cells of small, growing follicles, correlates with the number of small antral follicles (2 to $5 \mathrm{~mm}$ ) observed by transvaginal ultrasound in adult women $(52,53)$. AMH has also been considered a hallmark of polycystic ovarian syndrome (54). Villarroel and cols. (40), from our group, reported that girls with PCOM have higher AMH levels than girls without PCOM $(72.5 \pm 6.1$ vs. $33.4 \pm 2.6 \mathrm{pmol} / \mathrm{L} ; \mathrm{P}<0.000 \mathrm{l})$, and lower FSH levels $(5.4 \pm 0.3 ; 6.2 \pm 0.2 \mathrm{mUI} / \mathrm{ml} ; \mathrm{P}<$ 0.036). AMH levels positively correlated with the $2-5$ $\mathrm{mm}$ follicle number, and AMH levels above 60.15 $\mathrm{pmol} / \mathrm{L}$ had a sensitivity and specificity of 64.0 and $89.8 \%$, respectively, to diagnose PCOM by the Rotterdam criteria $(A U C=0.873)$. These data, together with the lack of hyperandrogenism or insulin resistance previously mentioned, suggest that PCOM in adolescent girls is a physiologic condition that may be linked to a large follicle mass. Future studies will evaluate the longterm consequences of high AMH levels and PCOM in healthy girls.

Thus, it is not clear whether PCOM is associated with HA during adolescence, and there is no consensus whether to include PCOM as a diagnostic criteria for PCOS in adolescent girls, because it may be part of normal ovarian physiology during this period (20).

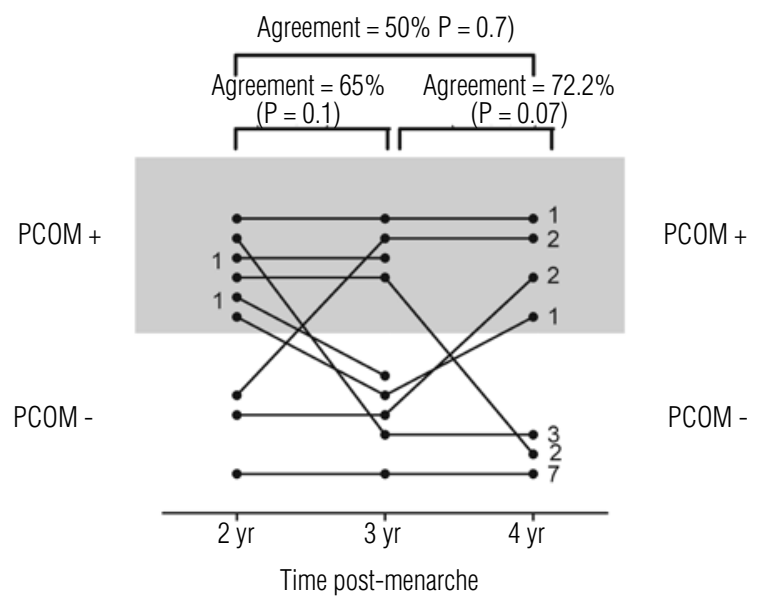

Figure 1.

\section{PREDISPOSING FACTORS}

Several authors have proposed that adult PCOS begins in childhood (55). Prenatal exposure to androgens, demonstrated in animal studies $(56,57)$, and in daughters of PCOS mothers (58-60), suggest that these conditions are associated with an adverse metabolic profile during childhood and puberty, similar to that seen in PCOS, and with higher AMH levels. Other predisposing factors may include low birth weight, premature pubarche, use of some drugs, type 1 diabetes, obesity and insulin resistance (61).

The prevalence of obesity is increasing in childhood and adolescence. Weight gain during adolescence carries a higher risk for early puberty, obesity and estrogendependent disease later in life, including polycystic ovary syndrome and breast cancer (62). A study regarding the association of obesity and hyperandrogenemia during the pubertal transition in 41 obese and 35 normalweight peripubertal girls, showed that BMI correlates with total testosterone, SHBG, and free testosterone $(\mathrm{P}<0.0001)$. The correlation of BMI with free testosterone is maintained after adjustment for age, pubertal stage, insulin, $\mathrm{LH}$, and dehydroepiandrosterone sulfate levels (63).

Insulin resistance (IR) has been implicated in the pathophysiology of PCOS, and has been associated with hyperandrogenism, possibly caused by increased secretion of androgens by the theca cells and reduced hepatic production of sex hormone binding globulin (SHBG) (64). Evaluation of IR by measuring insulin and HOMA are not part of the diagnostic criteria for PCOS in adult women. In addition, during adolescence there is a degree of IR which appears to be physiological, so these criteria to diagnose PCOS are not very useful during puberty.

It has been observed that androgen levels are related to the metabolic syndrome, increased abdominal fat and abnormal pro-inflammatory and hemostatic agents $(65,66)$. The altered metabolic profile observed in girls with PCOS is multifactorial and can be secondary to hyperandrogenemia, insulin resistance and obesity in an independent manner $(67,68)$. The cardiovascular risk observed in adult women with PCOS, can be assessed by the measurement of intima-media thickness (IMT), a good predictor of cardiovascular events in adulthood $(69,70)$. In 160 obese adolescents girls, the subgroup with the metabolic syndrome (48 girls) demonstrated significantly higher testosterone and DHEA-S concen- 
trations compared with the 112 girls without MS. Levels of testosterone correlated significantly with systolic and diastolic blood pressure, $2 \mathrm{~h}$ glucose in oGTT, triglycerides, uric acid, waist circumference and IMT (71).

In conclusion, the use of the three different sets of diagnostic criteria for PCOS in adults has resulted in the description of widely variable phenotypes in the presumably affected patients. These patients appear to have different long-term metabolic risks, as shown in Table 2, but several publications have shown that hyperandrogenism is the most important risk factor in these patients. During adolescence, there is no consensus as whether to use either the NIH or AES criteria to diagnose PCOS. We suggest that the diagnosis of PCOS should be based on the presence of hirsutism and biochemical hyperandrogenism, associated with menstrual cycles persistently longer than 45 days during adolescence. Intermediate phenotypes suspicious for PCOS should be followed closely during adolescence and stimulated to keep a healthy lifestyle and evaluated further during early adulthood, searching for signs of hyperandrogenism and ovulatory dysfunction. The diagnosis of PCOS carries a long-term stigma, so the temptation to make this diagnosis and consider medical therapy during adolescence should be tempered against the real benefits of such therapy, and the possible risks of the drugs employed to treat this condition.

Disclosure: no potential conflict of interest relevant to this article was reported.

Table 2. Proposed diagnostic criteria for polycystic ovarian syndrome in adolescence. Features: + Present, - Absent, +/- Controversial. The presence of a "V" indicates that this classification agrees that the diagnosis of PCOS phenotype. The diagnosis of oligo-anovulation and hyperandrogenism differ between adults and adolescents (see text). Adapted from "Merino P, Schulin-Zeuthen C, Codner E. Current diagnosis of polycystic ovary syndrome: expanding the phenotype but generating new questions. Rev Med Chil. 2009;137:1071-80" and "Azziz R, Carmina E, Dewailly D, et al. Positions statement: criteria for defining polycystic ovary syndrome as a predominantly hyperandrogenic syndrome: an Androgen Excess Society guideline. J Clin Endocrinol Metab. 2006;91:4237-45".

\begin{tabular}{|c|c|c|c|c|c|c|c|c|c|c|c|c|c|c|c|c|}
\hline \multirow[b]{2}{*}{ Diagnostic criteria } & \multicolumn{16}{|c|}{ Potential phenotypes } \\
\hline & A & B & C & D & $\mathbf{E}$ & $\mathbf{F}$ & G & H & 1 & $\mathbf{J}$ & K & $\mathbf{L}$ & $\mathbf{M}$ & $\mathbf{N}$ & 0 & $\mathbf{P}$ \\
\hline Biochemical hyperandrogenism & + & + & + & + & - & - & + & - & + & - & + & - & - & - & + & - \\
\hline Hirsutism & + & + & - & - & + & + & + & + & - & - & + & - & - & + & - & - \\
\hline Oligo-anovulation & + & + & + & + & + & + & - & - & - & + & - & - & + & - & - & - \\
\hline PCOM & + & - & + & - & + & - & + & + & + & + & - & + & - & - & - & - \\
\hline \multicolumn{17}{|l|}{ PCOS in adults } \\
\hline NIH 1990 & $\sqrt{ }$ & $\sqrt{ }$ & $\sqrt{ }$ & $\sqrt{ }$ & $\sqrt{ }$ & $\sqrt{ }$ & & & & & & & & & & \\
\hline Rotterdam 2003 & $\sqrt{ }$ & $\sqrt{ }$ & $\sqrt{ }$ & $\sqrt{ }$ & $\sqrt{ }$ & $\sqrt{ }$ & $\sqrt{ }$ & $\sqrt{ }$ & $\sqrt{ }$ & $\sqrt{ }$ & & & & & & \\
\hline AES 2006 & $\sqrt{ }$ & $\sqrt{ }$ & $\sqrt{ }$ & $\sqrt{ }$ & $\sqrt{ }$ & $\sqrt{ }$ & $\sqrt{ }$ & $\sqrt{ }$ & $\sqrt{ }$ & $\sqrt{ }$ & & & & & & \\
\hline PCOS in adolescence & $\sqrt{ }$ & $\sqrt{ }$ & $\sqrt{ }$ & $\sqrt{ }$ & $\sqrt{ }$ & $\sqrt{ }$ & $\sqrt{ }$ & $\sqrt{ }$ & $\sqrt{ }$ & $\sqrt{ }$ & & & & & & \\
\hline Our proposal & $\sqrt{ }$ & $\sqrt{ }$ & $+/-$ & $\sqrt{ }$ & $\sqrt{ }$ & $\sqrt{ }$ & $+/-$ & & & & & & & & & \\
\hline Long-term metabolic risk & $\sqrt{ }$ & $\sqrt{ }$ & $\sqrt{ }$ & $\sqrt{ }$ & $\sqrt{ }$ & $\sqrt{ }$ & $+/-$ & $+/-$ & $+/-$ & - & & & & & & \\
\hline
\end{tabular}

\section{REFERENCES}

1. Knochenhauer ES, Key TJ, Kahsar-Miller M, Waggoner W, Boots LR, Azziz R. Prevalence of the polycystic ovary syndrome in unselected black and white women of the southeastern United States: a prospective study. J Clin Endocrinol Metab. 1998;83(9):3078-82.

2. Carmina E, Oberfield SE, Lobo RA. The diagnosis of polycystic ovary syndrome in adolescents. Am J Obstet Gynecol. 2010;203(3):201.e1-5.

3. Shayya R, Chang RJ. Reproductive endocrinology of adolescent polycystic ovary syndrome. BJOG. 2010;117(2):150-5.

4. Stein I, Leventhal ML. Amenorrhea associated with bilateral polycystic ovaries. Am J Obstet Gynecol. 1935;29:181-91.

5. Zawadsky J, Dunaif A. Diagnostic criteria for polycystic ovary syndrome. In: Dunaif A, Givens JR, Haseltine FP, Merriam GR, ed. Polycystic ovary syndrome. Boston: Blackwell Scientific. 1992. p. 377-84.
6. The Rotterdam ESHRE/ASRM-Sponsored PCOS Consensus Workshop Group. Revised 2003 consensus on diagnostic criteria and long-term health risks related to polycystic ovary syndrome. Fertil Steril. 2004;81(1):19-25.

7. Azziz R, Carmina E, Dewailly D, Diamanti-Kandarakis E, Escobar-Morreale HF, Futterweit W, et al. Criteria for defining polycystic ovary syndrome as a predominantly hyperandrogenic syndrome: an androgen excess society guideline. J Clin Endocrinol Metab. 2006;91(11):4237-45.

8. Merino $P$, Schulin-Zeuthen $C$, Codner E. [Current diagnosis of polycystic ovary syndrome: expanding the phenotype but generating new questions]. Rev Med Chil. 2009;137(8):1071-80.

9. Fraser IS, Critchley HO, Munro MG, Broder M. Can we achieve international agreement on terminologies and definitions used to describe abnormalities of menstrual bleeding? Hum Reprod. $2007 ; 22(3): 635-43$. 
10. Diaz A, Laufer MR, Breech LL. Menstruation in girls and adolescents: using the menstrual cycle as a vital sign. Pediatrics. 2006;118(5):2245-50.

11. Adams Hillard PJ. Menstruation in adolescents: what's normal, what's not. Ann NY Acad Sci. 2008;1135:29-35.

12. Codner E, Eyzaguirre FC, Iniguez G, Lopez P, Perez-Bravo F, Torrealba IM, et al. Ovulation rate in adolescents with type 1 diabetes mellitus. Fertil Steril. 2011;95(1):197-202.e1.

13. Rosenfield RL. Clinical practice. Hirsutism. N Engl J Med. 2005;353(24):2578-88.

14. Martin KA, Chang RJ, Ehrmann DA, Ibanez L, Lobo RA, Rosenfield $R L$, et al. Evaluation and treatment of hirsutism in premenopausal women: an endocrine society clinical practice guideline. J Clin Endocrinol Metab. 2008;93(4):1105-20.

15. Ferriman D, Gallwey JD. Clinical assessment of body hair growth in women. J Clin Endocrinol Metab. 1961;21:1440-7.

16. Hatch R, Rosenfield RL, Kim MH, Tredway D. Hirsutism: implications, etiology, and management. Am J Obstet Gynecol. 1981;140(7):815-30.

17. Welt CK, Arason G, Gudmundsson JA, Adams J, Palsdottir H, Gudlaugsdottir $G$, et al. Defining constant versus variable phenotypic features of women with polycystic ovary syndrome using different ethnic groups and populations. J Clin Endocrinol Metab. 2006;91(11):4361-8.

18. Tellez R, Frenkel J. [Clinical evaluation of body hair in healthy women]. Rev Med Chil. 1995;123(11):1349-54.

19. Yildiz BO, Bolour S, Woods K, Moore A, Azziz R. Visually scoring hirsutism. Hum Reprod Update. 2010 Jun 30;16(1):51-64.

20. Hickey M, Doherty DA, Atkinson H, Sloboda DM, Franks S, Norman RJ, et al. Clinical, ultrasound and biochemical features of polycystic ovary syndrome in adolescents: implications for diagnosis. Hum Reprod. 2011;26(6):1469-77.

21. Gryngarten M, Bedecarras $P$, Ayuso S, Bergada C, Campo S, Escobar ME. Clinical assessment and serum hormonal profile in prepubertal hypertrichosis. Horm Res. 2000;54(1):20-5.

22. Azziz R, Carmina E, Dewailly D, Diamanti-Kandarakis E, Escobar-Morreale HF, Futterweit W, et al. The Androgen Excess and PCOS Society criteria for the polycystic ovary syndrome: the complete task force report. Fertil Steril. 2009;91(2):456-88.

23. Slayden SM, Moran C, Sams WM Jr, Boots LR, Azziz R. Hyperandrogenemia in patients presenting with acne. Fertil Steril. 2001;75(5):889-92.

24. Gonzalez ME, Cantatore-Francis J, Orlow SJ. Androgenetic alopecia in the paediatric population: a retrospective review of 57 patients. Br J Dermatol. 2010;163(2):378-85.

25. Azziz R, Sanchez LA, Knochenhauer ES, Moran C, Lazenby J, Stephens $\mathrm{KC}$, et al. Androgen excess in women: experience with over 1000 consecutive patients. J Clin Endocrinol Metab. 2004;89(2):453-62.

26. Matsumoto AM, Bremner WJ. Serum testosterone assays--accuracy matters. J Clin Endocrinol Metab. 2004;89(2):520-4.

27. Miller KK, Rosner W, Lee H, Hier J, Sesmilo G, Schoenfeld D, et al. Measurement of free testosterone in normal women and women with androgen deficiency: comparison of methods. J Clin Endocrinol Metab. 2004;89(2):525-33.

28. Hahn S, Kuehnel W, Tan S, Kramer K, Schmidt M, Roesler S, et al. Diagnostic value of calculated testosterone indices in the assessment of polycystic ovary syndrome. Clin Chem Lab Med. 2007;45(2):202-7.

29. Rosner W, Auchus RJ, Azziz R, Sluss PM, Raff H. Position statement: Utility, limitations, and pitfalls in measuring testosterone: an Endocrine Society position statement. J Clin Endocrinol Metab. 2007;92(2):405-13.

30. Willenberg HS, Bahlo M, Schott M, Wertenbruch T, Feldkamp J, Scherbaum WA. Helpful diagnostic markers of steroidogenesis for defining hyperandrogenemia in hirsute women. Steroids. 2008;73(1):41-6.

31. Mueller A, Cupisti S, Binder H, Hoffmann I, Kiesewetter F, Beckmann MW, et al. Endocrinological markers for assessment of hyperandrogenemia in hirsute women. Horm Res. 2007;67(1):35-41.

32. Taieb J, Mathian B, Millot F, Patricot MC, Mathieu E, Queyrel N, et al. Testosterone measured by 10 immunoassays and by isotope-dilution gas chromatography-mass spectrometry in sera from 116 men, women, and children. Clin Chem. 2003;49(8):1381-95.

33. Davison SL, Bell R, Donath S, Montalto JG, Davis SR. Androgen levels in adult females: changes with age, menopause, and oophorectomy. J Clin Endocrinol Metab. 2005;90(7):3847-53.

34. Rieder J, Santoro N, Cohen HW, Marantz P, Coupey SM. Body shape and size and insulin resistance as early clinical predictors of hyperandrogenic anovulation in ethnic minority adolescent girls. J Adolesc Health. 2008;43(2):115-24.

35. Bronstein J, Tawdekar S, Liu Y, Pawelczak M, David R, Shah B. Age of onset of polycystic ovarian syndrome in girls may be earlier than previously thought. J Pediatr Adolesc Gynecol. 2011;24(1):15-20.

36. Azziz R, Carmina E, Dewailly D, Diamanti-Kandarakis E, Escobar-Morreale HF, Futterweit W, et al. Positions statement: criteria for defining polycystic ovary syndrome as a predominantly hyperandrogenic syndrome: an Androgen Excess Society guideline. J Clin Endocrinol Metab. 2006;91(11):4237-45.

37. Jonard S, RobertY, Cortet-Rudelli C, Pigny P, Decanter C, Dewailly D. Ultrasound examination of polycystic ovaries: is it worth counting the follicles? Hum Reprod. 2003;18(3):598-603.

38. Jonard S, Robert Y, Dewailly D. Revisiting the ovarian volume as a diagnostic criterion for polycystic ovaries. Hum Reprod. 2005;20(10):2893-8.

39. Balen AH, Laven JS, Tan SL, Dewailly D. Ultrasound assessment of the polycystic ovary: international consensus definitions. Hum Reprod Update. 2003;9(6):505-14.

40. Villarroel C, Merino PM, Lopez P, Eyzaguirre FC, Van Velzen A, Iniguez $\mathrm{G}$, et al. Polycystic ovarian morphology in adolescents with regular menstrual cycles is associated with elevated anti-Mullerian hormone. Hum Reprod. 2011;26(10):2861-8.

41. Hart R, Doherty DA, Norman RJ, Franks S, Dickinson JE, Hickey $M$, et al. Serum antimullerian hormone (AMH) levels are elevated in adolescent girls with polycystic ovaries and the polycystic ovarian syndrome (PCOS). Fertility and sterility. 2010;94(3):1118-21.

42. Hickey M, Sloboda DM, Atkinson HC, Doherty DA, Franks S, Norman RJ, et al. The relationship between maternal and umbilical cord androgen levels and polycystic ovary syndrome in adolescence: a prospective cohort study. J Clin Endocrinol Metab. 2009;94(10):3714-20.

43. Codner E, Villarroel C, Eyzaguirre FC, Lopez P, Merino PM, Perez-Bravo F, et al. Polycystic ovarian morphology in postmenarchal adolescents. Fertil Steril. 2011;95(2):702-6.e1-2.

44. Hart R, Doherty DA, Norman RJ, Franks S, Dickinson JE, Hickey $M$, et al. Serum antimullerian hormone (AMH) levels are elevated in adolescent girls with polycystic ovaries and the polycystic ovarian syndrome (PCOS). Fertil Steril. 2010;94(3):1118-21.

45. Mortensen M, Rosenfield RL, Littlejohn E. Functional significance of polycystic-size ovaries in healthy adolescents. J Clin Endocrinol Metab. 2006;91(10):3786-90.

46. Murphy MK, Hall JE, Adams JM, Lee H, Welt CK. Polycystic ovarian morphology in normal women does not predict the development of polycystic ovary syndrome. J Clin Endocrinol Metab. 2006;91(10):3878-84.

47. Alsamarai S, Adams JM, Murphy MK, Post MD, Hayden DL, Hall $\mathrm{JE}$, et al. Criteria for polycystic ovarian morphology in polycystic ovary syndrome as a function of age. J Clin Endocrinol Metab. 2009;94(12):4961-70. 
48. Duijkers IJ, Klipping C. Polycystic ovaries, as defined by the 2003 Rotterdam consensus criteria, are found to be very common in young healthy women. Gynecol Endocrinol. 2010;26(3):152-60.

49. Polson DW, Adams J, Wadsworth J, Franks S. Polycystic ovaries--a common finding in normal women. Lancet. 1988;1(8590):870-2.

50. Farquhar CM, Birdsall M, Manning P, Mitchell JM, France JT. The prevalence of polycystic ovaries on ultrasound scanning in a population of randomly selected women. Aust N Z J Obstet Gynaecol. 1994;34(1):67-72.

51. Adams JM, Taylor AE, Crowley WF Jr, Hall JE. Polycystic ovarian morphology with regular ovulatory cycles: insights into the pathophysiology of polycystic ovarian syndrome. J Clin Endocrinol Metab. 2004;89(9):4343-50.

52. Pigny $P$, Jonard $S$, Robert $Y$, Dewailly D. Serum anti-Mullerian hormone as a surrogate for antral follicle count for definition of the polycystic ovary syndrome. J Clin Endocrinol Metab. 2006;91(3):941-5.

53. Visser JA, de Jong FH, Laven JS, Themmen AP. Anti-Mullerian hormone: a new marker for ovarian function. Reproduction. 2006;131(1):1-9.

54. Dewailly D, Pigny P, Soudan B, Catteau-Jonard S, Decanter C, Poncelet $E$, et al. Reconciling the definitions of polycystic ovary syndrome: the ovarian follicle number and serum anti-Mullerian hormone concentrations aggregate with the markers of hyperandrogenism. J Clin Endocrinol Metab. 2010;95(9):4399-405.

55. Franks S. Adult polycystic ovary syndrome begins in childhood. Best Pract Res Clin Endocrinol Metab. 2002;16(2):263-72.

56. Abbott DH, Barnett DK, Bruns CM, Dumesic DA. Androgen excess fetal programming of female reproduction: a developmental aetiology for polycystic ovary syndrome? Hum Reprod Update. 2005;11(4):357-74.

57. Recabarren SE, Padmanabhan V, Codner E, Lobos A, Duran C, Vidal $M$, et al. Postnatal developmental consequences of altered insulin sensitivity in female sheep treated prenatally with testosterone. Am J Physiol Endocrinol Metab. 2005;289(5):E801-6.

58. Sir-Petermann T, Maliqueo M, Angel B, Lara HE, Perez-Bravo F, Recabarren SE. Maternal serum androgens in pregnant women with polycystic ovarian syndrome: possible implications in prenatal androgenization. Hum Reprod. 2002;17(10):2573-9.

59. Crisosto N, Codner E, Maliqueo M, Echiburu B, Sanchez F, Cassorla $F$, et al. Anti-Mullerian hormone levels in peripubertal daughters of women with polycystic ovary syndrome. J Clin Endocrinol Metab. 2007;92(7):2739-43.
60. Sir-Petermann T, Codner E, Perez V, Echiburu B, Maliqueo M, Ladron de Guevara A, et al. Metabolic and reproductive features before and during puberty in daughters of women with polycystic ovary syndrome. J Clin Endocrinol Metab. 2009;94(6):1923-30.

61. Hernandez MI, Mericq V. Chapter 21: Polycystic Ovarian Syndrome. Brook's Clinical Pediatric Endocrinology, 6th edition 2010; Edited by Brook C, Clayton P, Brown R. Blackwell Publishing; 2009. p. 559-70.

62. Jasik CB, Lustig RH. Adolescent obesity and puberty: the "perfect storm". Ann NY Acad Sci. 2008;1135:265-79.

63. McCartney CR, Prendergast KA, Chhabra S, Eagleson CA, Yoo R, Chang RJ, et al. The association of obesity and hyperandrogenemia during the pubertal transition in girls: obesity as a potential factor in the genesis of postpubertal hyperandrogenism. J Clin Endocrinol Metab. 2006;91(5):1714-22.

64. Dunkel L, Sorva R, Voutilainen R. Low levels of sex hormone--binding globulin in obese children. J Pediatr. 1985;107(1):95-7.

65. Santoro N, Torrens J, Crawford S, Allsworth JE, Finkelstein JS, Gold EB, et al. Correlates of circulating androgens in mid-life women: the study of women's health across the nation. J Clin Endocrinol Metab. 2005;90(8):4836-45.

66. Sowers MR, Jannausch M, Randolph JF, McConnell D, Little R, Lasley B, et al. Androgens are associated with hemostatic and inflammatory factors among women at the mid-life. J Clin Endocrinol Metab. 2005;90(11):6064-71.

67. Coviello AD, Legro RS, Dunaif A. Adolescent girls with polycystic ovary syndrome have an increased risk of the metabolic syndrome associated with increasing androgen levels independent of obesity and insulin resistance. J Clin Endocrinol Metab. 2006;91(2):492-7.

68. Glueck CJ, Morrison JA, Friedman LA, Goldenberg N, Stroop DM, Wang P. Obesity, free testosterone, and cardiovascular risk factors in adolescents with polycystic ovary syndrome and regularly cycling adolescents. Metabolism. 2006;55(4):508-14.

69. Polak JF, Pencina MJ, Pencina KM, O'Donnell CJ, Wolf PA, D'Agostino RB Sr. Carotid-wall intima-media thickness and cardiovascular events. N Engl J Med. 2011;365(3):213-21.

70. Hurwitz Eller $\mathrm{N}$, Netterstrom B. The intima media thickness and coronary risk factors. Int Angiol. 2001;20(2):118-25.

71. de Sousa G, Brodoswki C, Kleber M, Wunsch R, Reinehr T. Association between androgens, intima-media thickness and the metabolic syndrome in obese adolescent girls. Clin Endocrinol (Oxf). 2010;72(6):770-4. 